Ger J Exerc Sport Res 2022 · 52:647-656 https://doi.org/10.1007/s12662-022-00796-0 Received: 31 March 2021

Accepted: 5 January 2022

Published online: 31 January 2022

(c) The Author(s) 2022

\section{Meaning of talent detection}

Research in the field of talent is very complex, not least because of the many influencing factors. What exactly talents are is intensively discussed in many scientific disciplines. Generally, a talent is described as a person who possesses outstanding potential in a particular domain, either over a range of activities and situations, or within a specialized and narrow field of expertise (Williams, 2000). In relation to sports, talents describe people who demonstrate exceptional ability compared to reference groups of similar biological developmental stage and similar lifestyle habits and the training already realized, which indicates that he or she will be able to achieve exceptional athletic performance in the long-term (Baker, Cobley, Schorer, \& Wattie, 2017). Retrospectively, a talent is someone who has already achieved demonstrable top performance in their career (e.g., in sports) (Hohmann, 2009). Indeed, the development from a youngster to an elite world class athlete is a long-term, multidimensional, and highly complex process that is becoming increasingly important for practitioners and researches alike (Martindale, Collins, \& Daubney, 2005). It became clear that top performance at a young age in particular does not always mean top performance at senior level, but that the paths of athletic talent are manifold (Güllich, Macnamara, \& Hambrick, 2021). Usually the process recognizing current participants (at an early stage of their development) who have the potential to excel in a particular sport in adulthood is called talent identification and development (TID) process (in mu-

Fabienne Spies (D) - Leonie Schauer · Tim Bindel • Mark Pfeiffer

Institut für Sportwissenschaft, Johannes Gutenberg-Universität Mainz, Mainz, Germany

\title{
Talent detection-importance of the will and the ability when starting a sport activity
}

sic, mathematics, sports, etc.) (Vaeyens, Lenoir, Williams, \& Philippaerts, 2008). Basically, the first step of this process includes talent detection followed by talent orientation (Pion, 2015) or talentidentification (Till \& Baker, 2020). Talent detection aims to motivate children to choose one or more sports in accordance with their own personality traits and which can take place both transitively and intransitively. A child's talent can be detected (transitive) and a child can detect his or her own talent (intransitive). It means the discovery of potential performance of kids who are not currently involved in the sports in question (Pion, 2015; Vaeyens, 2008).

Science is increasingly concerned with this path and the associated promotion of talent. For the purpose of understanding and mapping the development from athletic novice to elite performer, there are numerous models for long-term performance building (Baker, Côté, \& Abernethy, 2003). These can be roughly divided into different types in terms of their focus. On the one hand, there are process-oriented models that deal with the path and depict different stages on the way to the top, e.g., Long-Term Athlete Development Model (Balyi \& Hamilton, 2004), Developmental Model of Sport Participation (Côté, Baker, \& Abernethy, 2007), and Road to Excellence (Ericsson, Krampe, \& Tesch-Römer, 1993). On the other hand, there are structure-oriented models that list content and influencing factors that are necessary for the development of talent, e.g., Athletic Talent Development Environment Model (Henriksen, Stambulova, \& Roessler, 2010), Munich Model of
Giftedness (Heller, 2005), Multifactorial Gene-Environment Interaction Model (Hambrick, Burgoyne, Macnamara, \& Ullén, 2018), Differentiated Model of Giftedness and Talent (Gagné, 1993), and Model of Talent Development in Physical Education (Bailey and Morley, 2006). In summary, the basic assumption of the existing models is that there is a general interest in sports or a specific sport. At one of the first stages of the models, children with performance conspicuities are usually screened on the basis of various attributes, in order to be able to distinguish talent from nontalent and to find the suitable children for a specific sport (Baker, Schorer, \& Wattie, 2018). This can then be classified in the area of talent identification.

The listed models do not consider the phase of entry into the sport (talent detection) (Pion, 2015). How the process of detection turns out is open because first the discovery phase should lead to mastering and accompanying current situations. The measures of talent detection should lead to "getting interested in an area" even before talent identification occurs (Pion, 2015). In the following, the early phases of a sport activity will be examined from various perspectives using existing concepts in order to illustrate that even the entry into sport requires a differentiated view.

The aim of the article is to provide an overview of which factors are particularly relevant in early stages of talent detection and how these have already been researched in various disciplines. Furthermore, based on an already existing research framework, on intersections and gaps, an orientation framework for con- 


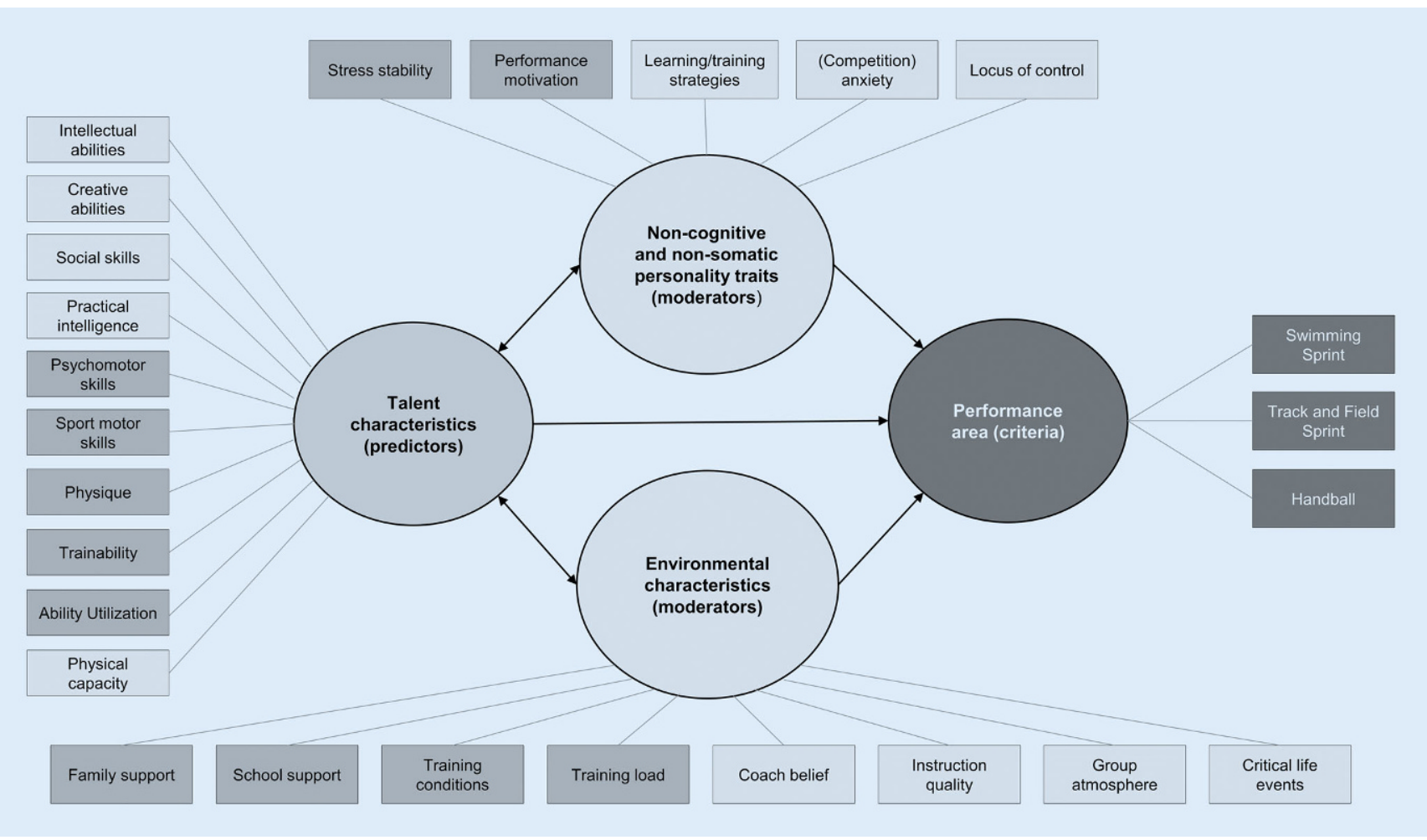

Fig. $1 \Delta$ Munich Model of Giftedness (Heller, 2005) adapted to sports (Hohmann, 2009)

ceptual research in sports science will be proposed. From this, intervention steps should be derived in the future.

\section{Concepts of talent development}

A review of the current literature on talent development reveals a broad spectrum of research methodological approaches from different scientific disciplines. In order to be able to map possible influencing factors in the process of talent detection in particular, various models of talent development have been proposed (often based on giftedness and talent) (Subotnik, Olszewski-Kubilius, \& Worrell, 2011). Some of the talent development models described are designed to explain the evolution of talent over time, going beyond the school years into adult eminence (Subotnik et al., 2011). Other models emphasize content and influencing factors, so that the individual develops as an integrative organism and thus acts actively as a whole (Bailey \& Morley, 2006).

Across disciplines, Heller (2005) summarizes in the Munich Model of Giftedness the tripartite of noncognitive personality traits (achievement motivation, striving for cognition, self-concept, etc.), giftedness factors (intelligence, creativity, psychomotor skills, etc.), and environmental characteristics (parents' educational level, number of siblings, critical life events, etc.) as those essential building blocks that interact to result in a person's achievement in a particular domain. Since the development of these models such as the Munich Model of Giftedness (Heller, 2005), it has become clear that in the dynamic process of talent development, both predictors (intellectual and non-intellectual), various criteria (e.g., performance) and moderators (environment; personality) play an essential role. These individual forms of giftedness, which are usually not always easily distinguishable, can more or less clearly be linked with certain achievement areas (e.g., mathematics, languages, conduct, music, sports) (Baker et al., 2017). Hohmann (2009) adapted the Munich Model of Giftedness to sports (- Fig. 1). The model includes moderators that affect the long-term development of complex competitive performance from childhood through adolescence and into adulthood. Taking these aspects into account, Hohmann (2009) distinguishes between, among other things, sport motor skills, trainability, psychomotor competences, and ability utilization regarding them as individual ability potentials. The noncognitive personality features include for example performance motivation, dealing with (competition) anxiety, as well as working and training strategies, which prove relevant for the acquisition of expertise.

This model does not consider timerelated steps, while different psychological models aim to describe achievement and focus on its development in different domains. Preckel et al. (2020) combine the influencing factors over time and thus map a development process that has not yet been received in sports science. With the Talent Development in Achievement Domains (TAD) framework, the authors provide a general talent development framework applicable to a wide range of achievement domains, such as Sports Science (• Fig. 2). The TAD framework is the first to map the importance of these influencing factors 
at different stages of development and across different performance domains. It is precisely these aspects that are crucial for identifying and promoting talent development. The TAD maps achievement development from elementary school age to adulthood and can be adapted to different achievement domains (such as music, or mathematics). A special feature of this framework model is the integration of different perspectives on achievement development (e.g., intelligence, giftedness, and expertise research). In order to pursue the aim of the article focusing on talent detection special attention will be paid to the upper part of the model (Aptitude and Competence).

What is noteworthy in Preckel's model compared to Heller's is that the personal factors are in focus, whereas the environmental factors are of minor importance. According to Preckel et al. (2020) ability-personality profiles are useful for talent development. A process of ability differentiation associated with the development of nonability factors leads to the formation of ability-personality profiles that differ across people. These profiles consist of individual constellations of abilities, interests and values, motivational variables, or self-concepts that predict further talent development across a wide range of performance levels, including exceptional performance (Ackerman \& Heggestad, 1997). Although mean levels of achievement-related factors are useful for predicting the achievement level of an individual, an individual's ability-personality profile is useful for predicting domain selection and the domain in which the person achieves best (Coyle, Purcell, Snyder, \& Richmond, 2014; Wang, Ye, \& Degol, 2017).

But what are the individual components of these profiles, what causes them to be formed, and what role do they play in entry into the sport? Preckel et al. (2020) initially summarize the two developmental levels of Aptitude and Competence. Aptitude refers to individual constellations of psychological factors that predispose a person to certain degrees of interest or engagement in an activity, which in turn are relevant to a particular domain of performance. Competence refers to a set of interrelated and system- atically developed skills, knowledge, and abilities that result from systematic learning and enable a person to act effectively in a situation.

Evidence on this level-dependent contents can be found in various disciplines regarding the start of an activity. Preckel et al. (2020) give examples for the arts, mathematics, and visual arts, but encourages transfer to other domains, considering research gaps and domain-specific characteristics.

\section{Sport-specific evidence in the first parts of the TAD framework}

Although the transfer of the TAD framework to sport is not entirely trivial and deviations occur at individual interfaces, parallels can nevertheless be found in various disciplines of Sport Science. Models based in sports, such as the Developmental Model of Sport Participation (DMSP) (Côté et al., 2007) already provide guidance on long-term performance building and the various stages of the development process. Predictors and indicators out of the TAD framework can be used as contents and contributing components (factors) to examine the individual stages of talent development in even greater detail. In this context, predictor means influencing factors to solve current sporting tasks, rather than making a prognosis.

\section{Aptitude}

One area of much research is domainspecific aptitude. This includes for example abilities, more precise in sports, this mostly refers to physiological and physical abilities such as body dimensions (Lopes, Rodrigues, Maia, \& Malina, 2011). Assuming a high general ability across sports (close to entry level), physical and physiological parameters play a role in sports. If you want to display abilities and thus aptitude, motor control is a possible predictor of general physical activity in 6- to 10-year-old children (Lopes et al., 2011). These parameters are often the subject of talent checks (Pion, Lenoir, Vandorpe, \& Segers, 2015; Platvoet et al., 2018), which are predominantly located in institutionalized sports. If a motor trait turns out
Ger J Exerc Sport Res 2022 · 52:647-656 https://doi.org/10.1007/s12662-022-00796-0 (c) The Author(s) 2022

F. Spies $\cdot$ L. Schauer $\cdot$ T. Bindel $\cdot$ M. Pfeiffer

Talent

detection-importance of the will and the ability when starting a sport activity

\section{Abstract}

The early identification of sports talents includes finding the right sport and is of great importance for both scientists and practitioners. In this article, special attention will be paid to the entry into sports in general as a basis of a talent development process. Sport-specific evidence from a variety of talent development models will be listed and research gaps will be identified. For this purpose, this article refers to a model that can be classified as both process and structure oriented and tries to find domain-specific application. A framework is presented as a research approach in which the different scientific disciplines can bring together their subject areas. This enables socalled ability-personality profiles consisting individual constellations of motivation variables, interests, skills, and experience to be studied together and incorporated into the talent development process. The arrangement of movement offers should be oriented to the individual profiles. At the same time, movement experiences can offer the basis for the formation of interests, motivation, and sport-motor skills, i.e., of the will and the ability. Taking the will into account as well as the ability could lead people to detect their own talent (based on contents of the presented framework) and the sport that is suitable for them, and thus be ready for the entry to the path of talent development.

\section{Keywords}

Talent detection - Ability-personality profile Children's interests . Finding your sport .

Talent development

to be a suitable predictor of later peak performance, this trait is included in the early process of talent identification. The goal is to find above-average children. In addition to this criterion of performance conspicuity, Hohmann (2001) describes the relative development speed, utilization and resilience as three further performance diagnostic criteria of sporting talent. The relative development speed considers the dependence of the performance 


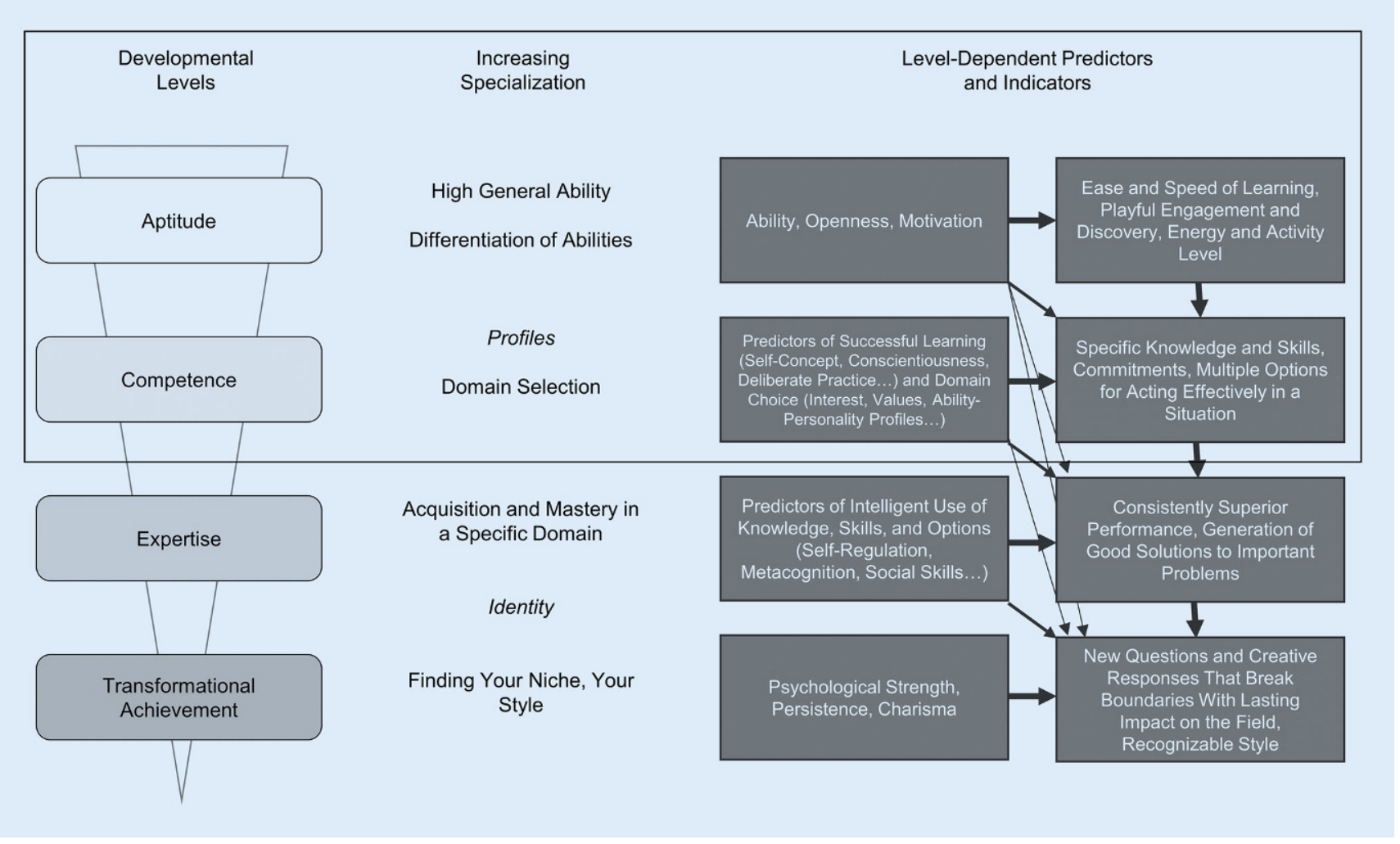

Fig. $2 \Delta$ The Talent Development in Achievement Domains (TAD) framework (Preckel et al., 2020). The rectangle shows the area relevant to this article (Levels Aptitude and Competence)

progress on the already achieved performance level. Utilization means that the highest possible performance is to be achieved with the most economical use of resources. Accordingly, young athletes are particularly suitable for achieving outstanding competitive performance with rather undeveloped age-related performance prerequisites. In this case, there is the opportunity to systematically develop the full capacity of the performance and development reserves and to carefully unfold them up to the individual maximum performance (Hohmann, 2009).

Motives are a central psychological prerequisite for sports activities (Lehnert, Sudeck, \& Conzelmann, 2011). They are distinguished by psychologists as implicit and explicit motives (Wegner \& Schüler, 2015). Here, only the implicit motives (e.g., achievement motive) are related to physiological (e.g., endocrine) parameters (Wegner \& Schüler, 2015). To this end, Wegner and Teubel (2014) were able to predict the near-competitive game performance of sport students in handball, soccer, and basketball via the achievement motive. The concept of implicit motives attempts to explain the direction, intensity, and persistence in the pursuit of goals (McClelland, 1987). In sports, for example, this is used to try to predict performance and well-being (Hänsel, Baumgärtner, Kornmann, \& Ennigkeit, 2016). Wegner and Schüler (2015) describe implicit motives as being associated with spontaneously and repeatedly exhibited long-term behavioral trends. Furthermore, according to Wegner and Schüler (2015), the fit between a person's implicit motives and motivational self-images, own goals, or situational incentives leads to improved wellbeing, stronger motivation, and thus better athletic performance.

Related to sports, the theory of planned behavior (Ajzen, 1985) can also be used to predict that the greater the perceived control of variables influencing participation in sport (e.g., one's own ability), the more positive the attitude and the subjective norm (evaluation) toward sport activity. This results in a greater intention to participate in sport, from which the intended behavior (actual sport activity) is most likely to follow (Alfermann \& Stoll, 2017). The theory seems particularly promising for both explaining and binding to sports programs and, conversely, for explaining dropouts or refusals to participate in sports. Previous theories in the field of sports can be summarized to the effect that besides social support and encouragement (e.g., from coaches), attitude toward sports is a crucial determinant for intention formation and thus for motivation to participate in sports. Influencing attitudes is therefore an important first step in motivating people to participate in sports (Alfermann \& Stoll, 2017; Hagger, Chatzisarantis, \& Biddle, 2002). In addition, perceived behavioral control and the conviction that one can do it (self-efficacy) have a positive effect on motivation (Hagger et al., 2002).

The role that motivational competence and interest play in inactive adults' choice of the right sport has also been recently clarified by Schorno, Sudeck, Gut, Conzelmann, and Schmid (2021). 
They emphasize the need for a guided reflection with a counsellor about experienced activities (e.g., What did you like? Why did you (not) like it?) which could help people to find an exercise and sport activity that suits them. Cross-cutting movement experiences and sport sessions might be helpful to gain experiences and understand the incentives of different activities (Schorno et al., 2021). This can mean both a cross-sport experience and a versatile experience within a specific sport. When experiencing various sports, the pedagogues recommend these conceptual and reflexive (Bindel, Herzberg, \& Schauer, 2021). According to this, sport is practiced based on interest and absolutely needs the exchange with children about their perspective (child perspective). If there is certainty that sport can be given individual meaning, the likelihood is increased that young people will gain something out of the educational potential of sport and will also be active with pleasure in the long term (Bindel et al., 2021).

Several studies show that, at least in the retrospective view, early specialization does not favor the development of elite athletes and before adolescence, diverse sports participation is more important (Barth, Emrich, \& Güllich, 2019; Kliethermes et al., 2020). In a cross-sectional study conducted by Fransen et al. (2012), 735 boys in three age groups (6-12 years) were profiled using a fitness test battery consisting of tests for strength, flexibility, speed and agility, cardiovascular endurance, and gross motor coordination. The results suggest an acute positive effect of many hours in sports and a latent positive effect of early sampling on fitness and gross motor coordination. Multiple comparisons revealed that boys aged 10-12 years, who spent many hours in various sports, performed better on standing broad jump $(p<0.05)$ and gross motor coordination $(p<0.05)$ than boys specializing in a single sport (Fransen et al., 2012). Beyond that, Güllich et al. (2021) were able to illustrate in their meta-analysis that, especially in the long term, diversification has a very positive impact on performance development compared to early specialization.
In general, it seems important to create positive experiences (not only through a variety of sports, but also through versatile experience within a sport and diverse forms of mediation) in order to offer every child, if possible, a space in which they can find themselves. This will not only generate interest and develop positive attitudes towards sports in general, (Alfermann \& Stoll, 2017; Singh, Voigt, \& Hohmann, 2015), but it could possibly also reduce the dropout rate.

In this context, it is important to point out that a not inconsiderable number of those who enter the process also exit, at different points in time of the model. This is not only necessary, but also intentional. In addition to the differentiated consideration of the reasons for exits, a distinction must be made between dropouts from the overall system and dropouts from the stringent path toward the top. The latter can still allow for performance-oriented organized sports activities, even if they are not internationally competitive. But dropouts also occur at early points (shortly after entry). According to a review from Crane and Temple (2015), intrapersonal constraints were by far the most prevalent group of factors, having been identified in almost $90 \%$ of the studies. Two of these factors, lack of enjoyment and perceptions of physical competence, were identified in more than half of all studies. Rarely were enjoyment or perceptions of competence unpacked in terms of why children and adolescents were nolonger enjoying sport or what sources of information were used to form these perceptions (Crane \& Temple, 2015). In a qualitative study of McCarthy and Jones (2007), it was summarized that children in the sampling years experience enjoyment from intrinsic and extrinsic sources that are both achievement and nonachievement related (Scanlan, Stein, \& Ravizza, 1989). Children in the latter stages of the sampling years do report other enjoyment and nonenjoyment sources compares with children who have just entered the sampling years (McCarthy \& Jones, 2007). Younger children named for example movement sensations as a source of enjoyment and punishment for skill errors as a source of nonenjoyment, while older children re- fer to social recognition of competence as a source of enjoyment and rivalry as a source of nonenjoyment. This supports the notion of developmental progression of emotional responses and can help coaches, parents and researchers develop more enjoyable experiences.

\section{Competence}

At the competence level, sport is already about sport-specific skills. Here, athletes have already found their domain and are tested for sport-specific parameters. These are measured in the form of various ability tests (e.g., Handball tests, Deutscher Handballbund (2019)) and the results are used to decide whether they are suitable and sufficient for the target sport.

A comparison between adolescent athletes from different types of sports makes it clear that each sport is, to a certain extent, unique in terms of physical prerequisites (Duncan, Woodfield, \& alNakeeb, 2006; Vandorpe et al., 2012). For example, soccer players demonstrate high levels of both upper and lower body strength for sport-specific actions including throwing-in and kicking the ball (Reilly, Bangsbo, \& Franks, 2000), while kinematics and efficiency seems to be the main determinants for example in swimming (Morais, Silva, Marinho, Lopes, \& Barbosa, 2017), and motor coordination appears to be the key ingredient in gymnastics (Vandorpe et al., 2012). These sport-specific characteristics make it possible to discriminate between athletes of different sports (Opstoel et al., 2015). Frequently tested parameters are, for example, flexibility (sit and reach) for discriminating combat sports (Pion, Fransen, Lenoir, \& Segers, 2014), but also balance, jumping laterally, hopping on one leg over an obstacle, (Lopes et al., 2011), sprinting (Wilson et al., 2016), cardiovascular endurance runs, etc. Complementary to these physiological parameters, physical (anthropometric) characteristics, such as stroke length or arm span in swimming (Morais et al., 2017), play a determinant role, while height is crucial to make it to the top in volleyball (Duncan et al., 2006). 
Where the TAD framework lists motivation at the aptitude level, interests and ability-personality profiles seem to contribute to domain choice at the competence level. What starts with a trigger, sparked by environmental or text features (e.g., unexpected information), then develops into real interest (Hidi \& Renninger, 2006). Previous educational research has focused on two types of interest: situational and individual interest (Schraw \& Lehman, 2001). Situational interest refers to focused attention and the affective reaction that is triggered in the moment by environmental stimuli, which may or may not last over time (Hidi, 1990), whereas individual interest refers to a person's relatively enduring predisposition to re-engage particular content over time as well as to the immediate psychological state when this predisposition has been activated (Renninger \& Wozniak, 1985). Especially individual interest has been found to have a positive impact on attention, recognition, and recall (Renninger \& Wozniak, 1985), persistence and effort, academic motivation, and levels of learning (Hidi \& Renninger, 2006). Things that can be beneficial also when starting a sport activity. Building on the work of researchers who have suggested that situational interest supports the development of individual interest, the Four-Phase Model (Hidi \& Renninger, 2006) describes early phases of interest development as primarily consisting of focused attention and positive feelings. Whereas at the aptitude level, the aim is to generate a general interest in sports, at the competence level a directed interest in a specific sport develops.

So far, there have already been initial indications that due to the various goals, the variety of activities and the different ways of arranging an activity, motivational competence and interests might be important to maintain exercise and sport (Hidi \& Renninger, 2006; Rheinberg \& Engeser, 2018; Schorno et al., 2021). In addition, experiencing an activity as satisfying is important for longterm participation (Rheinberg \& Engeser, 2018).

Côté et al. (2007) provide different pathways in the area of entry into sport activity. Based on Ericsson et al. (1993) the path of early specialization offers optimal starting conditions for 10 years of deliberate practice (DP). These have been assumed to be the amount of practice years needed to achieve peak performance, particularly in the arts. DP was operationalized as any training activity that (a) is undertaken with the specific purpose of increasing performance (e.g., not for enjoyment or external rewards), (b) requires cognitive and/or physical effort, and (c) promotes skill development (Côté, Allan, Turnnidge, \& Erickson, 2020). These number must not be considered too strict in a sporting context, depending on the type of sport. The central assumption of the deliberate practice model, that the personal investment of time and effort gives athletes little pleasure and is only sustained because of sporting success, must also be critically questioned. Thus, the direction of this cause-effect hypothesis can also be interpreted in the opposite way: according to the sport commitment theory (Scanlan, Carpenter, Simons, Schmidt, \& Keeler, 1993) competitive sport training is pursued preciselybecause it is enjoyable (Hohmann, Lames, Letzelter, \& Pfeiffer, 2020). This in turn presupposes interest and motivation. As reported by Barth and Emrich (2020), the promotion of a young talent should be organized in such a way that at even in the end of an unsuccessful promotion process (as a loser on the criterion of sporting success), the young talent does not feel that the time has been misinvested. This requires a pedagogically oriented design and management of the training process, which emphasize autonomy, self-control, self-reflection and enrichment, which "refers to the rich variety of play, physical activities, games and sports, that children and youth experience prior to (as well as during) the specialization phase in talent pathways" (Ribeiro et al., 2021, p. 1116).

Besides DP self-concept is another predictor of successful learning. Positive effects of a distinct self-concept on performance can also be observed in sports. These are found in particular in connection with the physical self-concept, so that Findlay and Bowker (2009) emphasize personality as an essential aspect of sport participation. Higher levels of athleticism (competitive and elite) were found to be associated with higher selfconcept.

While a child still needs high general abilities at the aptitude level, sportspecific indicators are already used for selection at the competence level. The transition is continuous, but as soon as the focus is on a specific sport, the competence level begins. It is precisely at this point that the decision is made as to whether a child enters a sport and remains in it or not.

\section{Summary and derivation of a research approach}

Talent is not a stable characteristic. Regardless of which person ends up at the top, one may initially be talented for a small next step. In order to take a path in sports, it is important to have an interest in the sport. This interest can then be solidified in further steps (perhaps even in the talent development process) and mature into lasting interest (e.g., Prenzel, Krapp, \& Schiefele, 1986). The transition from the state of general sport aptitude to the start of a competitive sport career in a specific sport is based on different factors and indicators. There has been little research in this transition yet. This concerns especially the interaction of motivation, interest, ability, and intervention (previous movement and training experience). It could be beneficial to have a framework as a research approach in which different scientific disciplines are brought together (Glazier, 2017).

So far, work on talent detection in sport focuses predominantly on the sport-motor performance of children with the aim of deriving recommendations for the inclusion of sport-specific support (Pion et al., 2015; Vaeyens et al., 2008). Complex performance data from tests (competitions) are particularly problematic if they are used as rigid cut-off values for inclusion in a development process at an early stage in the development of young talent. This approach leads to selection errors that, for example, exclude unexpected high performers from a promotion process. Therefore, the selection process 


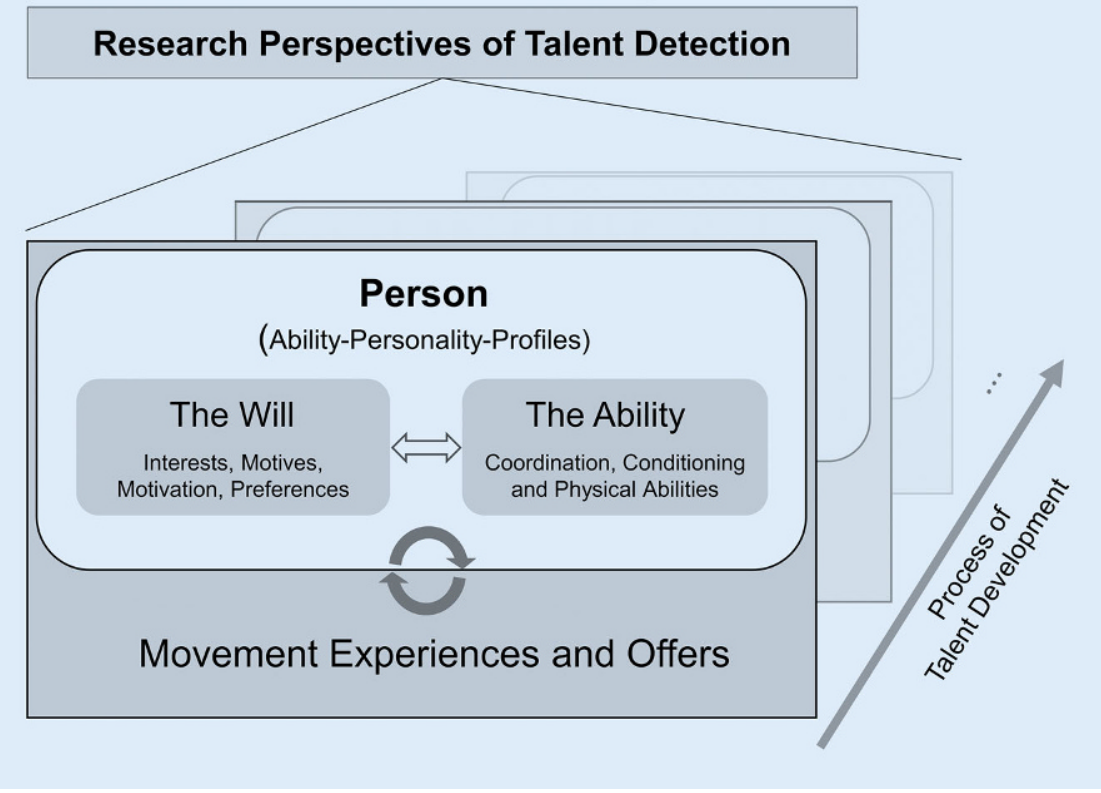

Fig. $3 \Delta$ Research perspectives of talent detection

has already been designed dynamically (Hohmann, 2009). However, empirical evidence that is available on motivation, interest, and mediation of sport opportunities has not been sufficiently considered in previous research on the process of talent detection.

If we summarize all the indicators, we could abstractly describe them as ability, will, and their arrangement (Movement Experiences and Offers). Even though there is already a lot of evidence on ability in particular, at the level of willingness (e.g., motivation and interest), there is a lack of reference to the talent issue and to the interfaces in childhood and at entry. Some influencing factors on this long way are hardly or still not at all controllable. Therefore, the first step is to get as many children as possible interested in sports and to investigate how children get into sports. This is because existing talent development processes assume entry into the sports system simply as given.

For talent development in sports, the Talent Development in Achievement Domains (TAD) framework is already a very good point of reference, where many areas can be transferred. Preckel et al. (2020) mention abilities and motivation as one level-dependent indicator, where unfortunately hardly any interfaces are known in sports at early levels. At later stages of the models (in adulthood), there are indications of intersections, e.g., the relationship between ability and achievement motivation (Zuber \& Conzelmann, 2014). It is necessary to take a closer look at the process of finding the sport that suits best from different perspectives because talent detection can take place both transitively and intransitively. It is agreed that child perspectives should be included, but how does a child find its domain, based on its physical and physiological prerequisites, its interests, and its motivation?

In order to provide orientation for talent research in sports, especially for the relevant parts in the field of talent detection, a framework will be offered in addition to the already existing models, which also encourages interdisciplinary research of the constructs ability, will(ingness) and their arrangement (- Fig. 3).

The central element of the present proposal is the person (athlete) who has a certain ability-personality profile. This profile includes the two areas of the will and the ability. When creating suitable (movement) offers for a person, both the abilities and the will should be considered. At the same time, previous experiences of different offers in turn result in characteristics of the abilities and the will. Thus, it is not only important to consider the current individual ability-personality profiles of a person, but in the field of talent development it is equally important to gather experiences to form these profiles (interest, motivation, etc.). Thus, over the time of the talent development process, there are always changes in the ability-personality profile and thus changes in the Movement Experiences and Offers. Research should thus survey all the above-mentioned perspectives of talent detection and take them into account in the context of selection measures. Further studies should also examine the stability of certain parameters of the framework, particularly in childhood, and the extent to which interest, for example, changes as a response to differentiated athletic experiences.

Talent identification research has generally been performed using univariate analysis, which ignores multivariate relationships with regard to the ability-personality profiles listed above. One of the first steps is to clarify how the two constructs of willingness and ability are related and mutually dependent. Furthermore, in talent research, quantitative methods are predominantly used. Nevertheless, "focus-group interviews offer a useful method of exploring the child's perspective on sport experiences in the sampling years, especially when one considers the struggles children encounter understanding and describing their emotional experiences" (McCarthy \& Jones, 2007, p. 413). Especially in the field of applied research, multiperspective approaches are considered an appropriate method. Through mixed-methods, one expects to better understand a complex problem by illuminating both sides, the quantitative side of counting and the qualitative side of comprehending sense (Kuckartz, 2014). The present proposal can offer a suggestion in this regard in the (sub)field of talent detection.

\section{Conclusion}

Although talent development is a process and predictors should be viewed dynamically over the long term, entry into sport is the start of any athletic process. Already at this point, numerous factors of 
willingness and ability play a role, which at best are examined and considered together with their arrangement. To inspire enthusiasm for sports, interest is of great importance. This is often assumed but has never been studied in connection with talent and, for example, in combination with one's own ability. In addition, there are indications of advantages of versatile movement offers, as in the research frame consisting of willingness and ability should be taken into account in order to proceed in an athlete-centered way (Ribeiro et al., 2021). Talent detection should no longer take place only transitively, but also intransitively. There is a need of interdisciplinary research to gain a multilayered understanding of the complex interrelationships, possibly also in a mix of methods. Particularly in the transition from aptitude to competence, concepts are needed in sport to understand how the will and the ability (ability-personality profiles) are related and influence the choice of a specific sport. There are indications that the arrangement of movement offers should therefore be oriented to the conditions of the will and the ability and at the same time movement experiences could offer the basis for the formation of interests, motivation, and sport-motor skills, i.e., of the will and the ability. Further research can be based on the framework to investigate how individual parameters of the ability-personality profiles are related and how these change beyond the time of entry (for example, through different movement offers).

\section{Corresponding address}

Fabienne Spies
Institut für Sportwissenschaft,
Johannes Gutenberg-
Universität Mainz
Albert-Schweitzer-Str. 22,
55128 Mainz, Germany
f.spies@uni-mainz.de

Funding. Open Access funding enabled and organized by Projekt DEAL.

\section{Declarations}

Conflict of interest. F. Spies, L. Schauer, T. Bindel and M. Pfeiffer declare that they have no competing interests.

For this article no studies with human participants or animals were performed by any of the authors. All studies performed were in accordance with the ethical standards indicated in each case.

Open Access. This article is licensed under a Creative Commons Attribution 4.0 International License, which permits use, sharing, adaptation, distribution and reproduction in any medium or format, as long as you give appropriate credit to the original author(s) and the source, provide a link to the Creative Commons licence, and indicate if changes were made. The images or other third party material in this article are included in the article's Creative Commons licence, unless indicated otherwise in a credit line to the material. If material is not included in the article's Creative Commons licence and your intended use is not permitted by statutory regulation or exceeds the permitted use, you will need to obtain permission directly from the copyright holder. To view a copy of this licence, visit http://creativecommons.org/licenses/by/4.0/.

\section{References}

Ackerman, P.L., \& Heggestad, E.D. (1997). Intelligence, personality, and interests: evidence for overlapping traits. Psychological Bulletin, 121(2), 219-245. https://doi.org/10.1037/0033-2909. 121.2.219.

Ajzen, I. (1985). From intentions to actions: a theory of planned behavior. In J. Kuhl \& J. Beckmann (Eds.), Springer series in social psychology. Action control: From cognition to behavior (1st edn., pp. 11-39). Berlin: Springer. https://doi.org/10. 1007/978-3-642-69746-3_2.

Alfermann, D., \& Stoll, O. (2017). Sportpsychologie: Ein Lehrbuch in 12 Lektionen [Sports psychology: a textbook in 12 lessons] (5th edn.). Sportwissenschaft studieren, Vol. 4. Aachen: Meyer \& Meyer.

Bailey, R., \& Morley, D. (2006). Towards a model of talent development in physical education. Sport Education and Society, 11(3), 211-230.

Baker, J., Cobley, S., Schorer, J., \&Wattie, N. (Eds.). (2017). Routledge Handbook of talent identification and development in sport. New York: Routledge.

Baker, J., Côté, J., \& Abernethy, B. (2003). Learning from the experts: practice activities of expert decision makers in sport. Research Quarterly for Exercise and Sport, 74(3), 342-347.

Baker, J., Schorer, J., \& Wattie, N. (2018). Compromising talent: issues in identifying and selecting talent in sport. Quest, 70(1), 48-63. https://doi.org/10. 1080/00336297.2017.1333438.

Balyi, I., \& Hamilton, A. (2004). Long-term athlete development: Trainability in childhood and adolescence. Olympic Coach, 16(1), 4-9.

Barth, M., \& Emrich, E. (2020). Talententwicklung im Fördersystem des Nachwuchsleistungssports [Talent development in the support system of young high performance sports]. In C. Breuer, C. Josten \& W. Schmidt (Eds.), Vierter Deutscher kinder- und Jugendsportbericht [Fourth German children's and youth sports report] (pp. 225-248). Schorndorf: Hofmann-Verlag.
Barth, M., Emrich, E., \& Güllich, A. (2019). A machine learning approach to "revisit" specialization and sampling in institutionalized practice. SAGE Open, 9(2), 215824401984055. https://doi.org/ $10.1177 / 2158244019840554$.

Bindel, T., Herzberg, S., \& Schauer, L. (2021). Bunte Bewegungswelten von Kindern und Jugendlichen: Interessenorientierung und Reflexion [Colorful worlds of movement for children and young people: Interest orientation and reflection]. Sportunterricht, 70(2), 64-70.

Coyle, T. R., Purcell, J. M., Snyder, A. C., \& Richmond, M. C. (2014). Ability tilt on the SAT and ACT predicts specific abilities and college majors. Intelligence, 46, 18-24. https://doi.org/10.1016/j.intell.2014. 04.008 .

Crane, J., \& Temple, V. (2015). A systematic review of dropout from organized sport among children and youth. European Physical Education Review, 21(1), 114-131. https://doi.org/10.1177/ 1356336 X14555294.

Côté, J., Allan, V., Turnnidge, J., \& Erickson, K. (2020). Early sport specialization and sampling. In G. Tenenbaum, R. C. Eklund \& N. Boiangin (Eds.), Handbook of sport psychology (pp. 578-594). Hoboken: Wiley.

Côté, J., Baker, J., \& Abernethy, B. (2007). Practice and play in the development of sport expertise (pp. 184-202).

Deutscher Handballbund (2019). Testmanual zur Leistungssportsichtung des DHB 2020 [Test manual for the DHB 2020 competitive sports screening]. Dortmund, Leipzig: DHB, AT.

Duncan, M. J., Woodfield, L., \& al-Nakeeb, Y. (2006). Anthropometric and physiological characteristics of junior elite volleyball players. British Journal of Sports Medicine, 40(7),649-651. https://doi.org/ 10.1136/bjsm.2005.021998. discussion 651.

Ericsson, K. A., Krampe, R. T., \& Tesch-Römer, C. (1993). The role of deliberate practice in the acquisition of expert performance. Psychological Review, 100(3), 363-406.

Findlay, L. C., \& Bowker, A. (2009). The link between competitive sport participation and self-concept in early adolescence: A consideration of gender and sport orientation. Journal of Youth and Adolescence, 38(1), 29-40. https://doi.org/10. 1007/s10964-007-9244-9.

Fransen, J., Pion, J., Vandendriessche, J., Vandorpe, B., Vaeyens, R., Lenoir, M., \& Philippaerts, R. M. (2012). Differences in physical fitness and gross motor coordination in boys aged $6-12$ years specializing in one versus sampling more than one sport. Journal of Sports Sciences, 30(4), 379-386. https://doi.org/10.1080/02640414. 2011.642808.

Gagné, F. (1993). Constructs and models pertaining to exceptional human abilities. In K. A. Heller, F.J. Mönks \& A.H. Passow (Eds.), International handbook of research and development of giftedness and talent. Oxford: Pergamon.

Glazier, P.S. (2017). Towards a grand unified theory of sports performance. Human Movement Science, 56(Pt A), 139-156. https://doi.org/10.1016/j. humov.2015.08.001.

Güllich, A., Macnamara, B. N., \& Hambrick, D. Z. (2021) What makes a champion? Early multidisciplinary practice, not early specialization, predicts world-class performance. Perspectives on Psychological Science. https://doi.org/10.1177/ 1745691620974772.

Hagger, M.S., Chatzisarantis, N.L.D., \& Biddle, S.J.H. (2002). A Meta-analytic review of the theories of reasoned action and planned 
behavior in physical activity: an examination of predictive validity and the contribution of additional variables. Journal of Sport and Exercise Psychology, 24(1), 3-32.

Hambrick, D.Z., Burgoyne, A. P., Macnamara, B. N., \& Ullén, F. (2018). Toward a multifactorial model of expertise: Beyond born versus made. Annals of the New York Academy of Sciences. https://doi. org/10.1111/nyas.13586.

Hänsel, F., Baumgärtner, S.D., Kornmann, J., \& Ennigkeit, F. (2016). Sportpsychologie [Sports psychology]. Berlin, Heidelberg: Springer. https://doi.org/10.1007/978-3-662-50389-8.

Heller, K. A. (2005). The munich model of giftedness and its impact on identification and programming. Gifted and Talented International, 20(1) 30-36. https://doi.org/10.1080/15332276. 2005.11673055.

Henriksen, K., Stambulova, N., \& Roessler, K. K. (2010). Successful talent development in track and field: Considering the role of environment. Scandinavian Journal of Medicine \& Science in Sports, 20(2), 122-132. https://doi.org/10.1111/ j.1600-0838.2010.01187.x.

Hidi, S. (1990). Interest and its contribution as a mental resource for learning. Review of Educational Research, 60(4), 549-571. https://doi.org/10. 3102/00346543060004549.

Hidi, S., \& Renninger, K. A. (2006). The four-phase model of interest development. Educational Psychologist, 41(2), 111-127. https://doi.org/10. 1207/s15326985ep4102_4.

Hohmann, A. (2001). Leistungsdiagnostische Kriterien sportlichen Talents [Performance diagnostic criteria of athletic talent]. Leistungssport, 31(4), 14-21.

Hohmann, A. (2009). Entwicklung sportlicher Talente an sportbetonten Schulen [Developing athletictalent at sport-focused schools]. Imhof: Petersberg.

Hohmann, A., Lames, M., Letzelter, M., \& Pfeiffer, M. (2020). Einführung in die Trainingswissenschaft [Introduction to exercise science] (7th edn.). Wiebelsheim, Hunsrück: Limpert

Kliethermes, S.A., Nagle, K., Côté, J., Malina, R.M., Faigenbaum, A., Watson, A., et al. (2020). Impact of youth sports specialisation on career and task-specific athletic performance: A systematic review following the American Medical Society for Sports Medicine (AMSSM) Collaborative Research Network's 2019 Youth Early Sport Specialisation Summit. British Journal of Sports Medicine, 54(4), 221-230. https://doi.org/10. 1136/bjsports-2019-101365

Kuckartz, U. (2014). Mixed Methods: Methodologie, Forschungsdesigns und Analyseverfahren. Wiesbaden: Springer VS. https://doi.org/10.1007/ 978-3-531-93267-5.

Lehnert, K., Sudeck, G., \& Conzelmann, A. (2011). BMZI - Berner Motiv- und Zielinventar im Freizeitund Gesundheitssport [BMZI - Motive and goal inventory in leisure and health sports from Bern] Diagnostica, 57(3), 146-159. https://doi.org/10. 7892/BORIS.10980.

Lopes, V.P., Rodrigues, L.P., Maia, J.A.R., \& Malina, R. M. (2011). Motor coordination as predictor of physical activity in childhood. Scandinavian Journal of Medicine \& Science in Sports, 21(5), 663-669. https://doi.org/10.1111/j.1600-0838. 2009.01027.x.

Martindale, R. J. J., Collins, D., \& Daubney, J. (2005) Talent development: a guide for practice and research within sport. Quest, 57,353-375.
McCarthy, P. J., \& Jones, M. V. (2007). A qualitatice study of sport enjoyment in the sampling years. The Sport Psychologist, 21,400-416.

McClelland, D.C. (1987). Human motivation. New York: Cambridge University Press.

Morais, J.E., Silva, A.J., Marinho, D. A., Lopes, V.P., \& Barbosa, T.M. (2017). Determinant factors of long-term performance development in young swimmers. International Journal of Sports Physiology and Performance, 12(2), 198-205. https://doi.org/10.1123/ijspp.2015-0420.

Opstoel, K., Pion, J., Elferink-Gemser, M., Hartman, E., Willemse, B., Philippaerts, R.M., et al. (2015). Anthropometric characteristics, physical fitness and motor coordination of 9 to 11 year old children participating in a wide range of sports. PLOS ONE, 10(5), e126282. https://doi.org/10. 1371/journal.pone.0126282.

Pion, J., Segers, V., Fransen, J., Debuyck, G., Deprez, D., Haerens, L., et al. (2015). Generic anthropometric and performance characteristics among elite adolescent boys in nine different sports. European Journal of Sport Science, 15(5), 357-366. https://doi.org/10. 1080/17461391.2014.944875.

Pion, J., Fransen, J., Lenoir, M., \& Segers, V. (2014). The value of non-sport-specific characteristics for talent orientation in young male judo, karate and taekwondo athletes. Archives of Budo, 10, 147-154.

Pion, J., Lenoir, M., Vandorpe, B., \& Segers, V. (2015). Talent in female gymnastics: a survival analysis based upon performance characteristics. International Journal of Sports Medicine, 36(11), 935-940. https://doi.org/10. 1055/s-0035-1548887.

Pion, J. (2015). The Flemish Sports Compass: From sports orientation to elite performance prediction (Dissertation). Ghent University, Ghent

Platvoet, S., Faber, I. R., de Niet, M., Kannekens, R., Pion, J., Elferink-Gemser, M. T., \& Visscher, C. (2018). Development of a tool to assess fundamental movement skills in applied settings. Frontiers in Education, 3, 12. https://doi.org/10.3389/feduc. 2018.00075 .

Preckel, F., Golle, J., Grabner, R., Jarvin, L., Kozbelt, A., Müllensiefen, D., et al. (2020). Talent development in achievement domains: a psychological framework for within- and crossdomain research. Perspectives on Psychological Science, 15(3), 691-722. https://doi.org/10. 1177/1745691619895030.

Prenzel, M., Krapp, A., \& Schiefele, H. (1986). Grundzüge einer pädagogischen Interessentheorie. Zeitschrift Für Pädagogik, 32, 163-173.

Reilly, T., Bangsbo, J., \& Franks, A. (2000). Anthropometric and physiological predispositions for elite soccer. Journal of Sports Sciences, 18(9), 669-683. https://doi.org/10.1080/02640410050120050.

Renninger, K.A., \& Wozniak, R.H. (1985). Effect of interest on attentional shift, recognition, and recall in young children. Developmental Psychology, 21(4), 624-632. https://doi.org/10. 1037/0012-1649.21.4.624.

Rheinberg, F., \& Engeser, S. (2018). Intrinsic motivation and flow. In J. Heckhausen \& H. Heckhausen (Eds.), Motivation and action (3rd edn., pp. 579-622). Cham: Springer. https:// doi.org/10.1007/978-3-319-65094-4_14.

Ribeiro, J., Davids, K., Silva, P., Coutinho, P., Barreira, D., \& Garganta, J. (2021). Talent development in sport requires athlete enrichment: contemporary insights from a nonlinear pedagogy and the athletic skills model. Sports Medicine (Auckland,
N.Z.), 51(6), 1115-1122. https://doi.org/10 1007/s40279-021-01437-6.

Scanlan, T.K., Carpenter, P. J., Simons, J.P., Schmidt, G. W., \& Keeler, B. (1993). The sport commitment model: measurement development for the youth-sport domain. Journal of Sport and Exercise Psychology, 15(1), 16-38. https://doi. org/10.1123/jsep.15.1.16.

Scanlan, T. K., Stein, G. L., \& Ravizza, K. (1989). An in-depth study of former elite figure skaters: II. Sources of enjoyment. Journal of Sport and Exercise Psychology, 11(1), 65-83. https://doi. org/10.1123/jsep.11.1.65.

Schorno, N., Sudeck, G., Gut, V., Conzelmann, A., \& Schmid, J. (2021). Choosing an activity that suits: development and validation of a questionnaire on motivational competence in exercise and sport. German Journal of Exercise and Sport Research, 51(1),71-78. https://doi.org/10.1007/ s12662-020-00698-z.

Schraw, G., \& Lehman, S. (2001). Situational interest: a review of the literature and directions for future research. Educational Psychology Review, 13(1), 23-52.

Singh, A., Voigt, L., \& Hohmann, A. (2015). Konzepte erfolgreichen Nachwuchstrainings (KerN) [Concepts of successful junior training]. Leistungssport, 2, 11-16.

Subotnik, R. F., Olszewski-Kubilius, P., \& Worrell, F.C. (2011). Rethinking giftedness and gifted education: a proposed direction forward based on psychological science. Psychological Science in the Public Interest: $A$ Journal of the American Psychological Society, 12(1), 3-54. https://doi. org/10.1177/1529100611418056.

Till, K., \& Baker, J. (2020). Challenges and possible solutions to optimizing talent identification and development in sport. Frontiers in Psychology, 11, 664. https://doi.org/10.3389/fpsyg.2020. 00664.

Vaeyens, R., Lenoir, M., Williams, A. M., \& Philippaerts, R. M. (2008). Talent identification and development progammes in sport. Sports Medicine, 38(9), 703-714.

Vandorpe, B., Vandendriessche, J.B., Vaeyens, R., Pion, J., Lefevre, J., Philippaerts, R. M., \& Lenoir, M. (2012). The value of a non-sport-specific motor test battery in predicting performance in young female gymnasts. Journal of Sports Sciences, 30(5), 497-505. https://doi.org/10. 1080/02640414.2012.654399.

Wang, M.T., Ye, F., \& Degol, J.L. (2017). Who chooses STEM careers? Using a relative cognitive strength and interest model to predict careers in science, technology, engineering, and mathematics. Journal of Youth and Adolescence, 46(8), 1805-1820. https://doi.org/10.1007/ s10964-016-0618-8.

Wegner, M., \& Schüler, J. (2015). Implizite Motive Perspektiven im Kontext Sport und Bewegung [Implicit motives-perspectives in the context of sport and exercise]. Zeitschrift Für Sportpsychologie, 22(1), 2-5. https://doi.org/10.1026/ 1612-5010/a000140.

Wegner, M., \& Teubel, T. (2014). The implicit achievement motive predicts match performances and the explicit motive predicts choices for target distances in team sports. International Journal of Sport Psychology, 45(6), 621-638.

Williams, M. R. (2000). The war for talent: Getting the best from the best. London: Chartered Institute of Personnel and Development.

Wilson, R.S., James, R.S., David, G., Hermann, E., Morgan, O.J., Niehaus, A.C., et al. (2016). 


\section{Main Article}

Multivariate analyses of individual variation in soccer skill as a tool for talent identification and development: Utilising evolutionary theory in sports science. Journal of Sports Sciences, 34(21), 2074-2086. https://doi.org/10.1080/02640414. 2016.1151544.

Zuber, C., \& Conzelmann, A. (2014). The impact of the achievement motive on athletic performance in adolescent football players. European Journal of Sport Science, 14(5), 475-483. https://doi.org/ 10.1080/17461391.2013.837513. 